\title{
Development and Performance Evaluation of a Rain Shade for a low scale Agricultural Produce
}

\section{*11MUSA NICHOLAS AKHAZE; ADEBAYO ADESHINA BAMIDELE}

\author{
Mechanical Engineering Department, \\ Federal University of Technology, Minna, Niger state, Nigeria \\ *Corresponding Author. Email address: Madonick1@yahoo.com GSM NO: 08058717209 \\ Co-author,s Email address: bamishinaadebayo@gmail.com
}

\begin{abstract}
This paper reports on the development and performance evaluation of a rain shade for a low scale agricultural produce, The rain shade consists of a geared D. C motor, $12 \mathrm{~V}$ battery, sensor, a roller tube in which a polyester fabric is wound, two extension arms attached directly to the roller tube that pulls out the fabric when the device is open to protect a designated area from rain and pulls it back when the rain stops and a stand. On performance evaluation of the rain shade, it was to able protect maize cobs by opening in average periods of $0.5,1,1$ and 1 second and retracting in average periods of $150,411,470$ and 480 seconds respectively. (C) JASEM
\end{abstract}

\section{http://dx.doi.org/10.4314/jasem.v19i2.13}

KEYWORDS: rain, rain shade, extension arm, weight, time

\section{INTRODUCTION}

In many agricultural countries, large quantities of food products are dried to improve shelf life, reduce packaging cost, lower weights, enhance appearance, retain original flavor and maintain nutritional value (Saeed et al, 2008). The examples of the products that are dried include cereals,oilseeds legumes and some processed food(Jayas and Singh,2014).The major objective of drying food products is the reduction of moisture content to a level which allows safe storage over an extended period (Sahari and Driscoll,2013). Sun drying of agricultural produce is the earliest and traditional method of reducing their moisture content . Although with appropriate harnessing technology, solar dryer evolved,sun drying is widely used in developing countries and most especially in the rural areas. This method involves spreading the agricultural produce in a tray or the ground or raised platform which is aerated and exposed to sunlight. Alamu et al(2014) opined that since the agricultural produce are laid in the open sky, there is greater risk of spoilage due to adverse climatic conditions like rain, moist among others.

Sun drying of agricultural produce is efficient and less labour intensive during dry season but during raining season, it is tasky in the sense that the agricultural produce has to be watched over and evacuated when there is rain Adebayo(2014). So in order to reduce this burden, the development of a rain shade was embarked on in this research work.

\section{MATERIALS AND METHOD}

Design theory and calculations: The following parts were considered for the design. 1. Geared D.C motor, 2. The Extension Arm 3. Roller tube and 3.Stand as column

Determination of Torque transmitted by the D.C Motor: A geared D.C motor having a speed of 2500r.p.m powered by 12 volts and 5 ampere is used to drive the rain shade system. The power input by the motor is given by; $P_{I}=I V \quad$ (1) The angular $\begin{array}{ll}\text { speed }(w) \text { is given by; } \quad w=\frac{2 \pi N}{60} & \text { (2) The torque }\end{array}$ developed $(\mathrm{T})$ according to khurmi and Gupta (2005), is given as; $\quad T=\frac{P \times 60}{2 \pi N}$

Design of Worm Gear: The worm gear is used to reduce the speed of the roller tube while increasing the final torque transmitted to the roller tube, using a velocity ratio(V.R) of 10:1. Torque developed by the worm gear, which is the final torque transmitted to the device $\left(\mathrm{T}_{\mathrm{f}}\right) ; \quad T_{f}=T \times V \cdot R$ (4)

According to khurmi and Gupta (2005), the number of teeth on the worm gear $\mathrm{T}_{\mathrm{G}} ; \mathrm{T}_{\mathrm{G}}=V . R \times T_{W}$ (5) According to Bhandari(2014), the recommended value of $(\mathrm{m})$ for general purpose worm gear with V.R $10: 1$ and a $80 \mathrm{~mm}$ centre distance is 4 . From khurmi and Gupta(2005), the pitch circle diameter of the gear , $D_{G}=m \times T_{G}$ 
The outside diameter $\mathrm{D}_{\mathrm{OG}} \quad D_{O G}=D_{G}+0.8903 P_{C}$ (7) . Axial pitch $\mathrm{p}=\pi \times \mathrm{m}$ (8) Throat diameter, $D_{T}=D_{G}+0.572 P_{C}$ (9) Face width, $\mathrm{b}=2.15 p_{c}+$ $5 \mathrm{~mm}(10)$

Determination of weight acting on the Extension Arm: The measured weight of the polyester fabric equals $14.7 \mathrm{~N}$, while the combined measured weights of the two PVC lead tubes equal $4.9 \mathrm{~N}$, the two sleeves have a combined weight of $0.5 \mathrm{~N}$. The sum of all these weights gives the total weight acting on the extension arm.

Weight acting on each extension arm $=\frac{\text { Total weight }}{2}$

Determination of Roller Tube Diameter: It is powered by the D.C motor and also has imbedded in it the springs which extends and retracts accordingly. It is $1.2 \mathrm{~m}$ in length. It is made of timber with shear strength of $2.2 \mathrm{Mpa}$ and its factor of safety is 8 . (www.woodsolutions.com).

allowable shear stress, $\tau=\frac{\text { maximum shear stress }}{\text { factor of safety }}$

(12) According to Khurmi and Gupta (2005), twisting moment, $\mathrm{T}$ is given as $T=\frac{\pi \times \tau\left(d_{o}^{3}\right)(1-k)^{4}}{16}$ (13)

Where $d_{o}$ and $d_{i}$ are the outer and inner diameter of the roller tube.

Determination of load carrying capacity of the stand:The material used for the stands is a mild steel $25 \mathrm{~mm}$ square hollow pipe, having thickness of $1 \mathrm{~mm}$, with a crushing stress of $320 \mathrm{~N} / \mathrm{mm}^{2}$ and Young Modulus, E of $0.21 \times 10^{6} \mathrm{~N} / \mathrm{mm}^{2}$. According to Khurmi and Gupta(2005), crushing stress $=\frac{c \pi^{2} E}{\left(\frac{l}{k}\right)^{2}}$ (14)

Where $\mathrm{C}=$ Constant of end condition $=0.25, \mathrm{~L}=$ Equivalent length of the stand, $\mathrm{K}=$ Radius of gyration and $\frac{l}{k}=$ slenderness ratio

The radius of gyration is given by Hall et al(2004)as $\mathrm{k}=\frac{h \sqrt{3}}{6} \quad$ (15) where $\mathrm{h}=\mathrm{b}=25 \mathrm{~mm}=$ the width of the hollow square pipe. The actual length of the pipe is $1000 \mathrm{~mm}$, so the equivalent length of the pipe is $2000 \mathrm{~mm}$

Euler formula was used to calculate the buckling load of the stand, in line with the conditions given by Khurmi and Gupta(2005). The buckling load $w_{c r}=\frac{c \pi^{2} E I}{l^{2}} \quad$ (16) The least moment of inertia of section of the column $\mathrm{I}=\frac{B D^{3}}{12}-\frac{b d^{3}}{12} \quad$ (17) Where D $=B=$ Depth of the outer section $=25 \mathrm{~mm}$ and $\mathrm{d}=\mathrm{b}=$ $23 \mathrm{~mm}=$ The depth of the inner section of the hollow square pipe.

Development of the Sensor Unit: The rain sensor was purchased and installed. It has the following technical specifications: Power supply rated voltage is DC $15-30 \mathrm{~V}$, current consumption approximately $10 \mathrm{Ma}$. Heating rated voltage is $\mathrm{AC} / \mathrm{DC} 24 \mathrm{~V}$ and maximum power consumption of $4.5 \mathrm{~W}$.

The exploded views and assembly drawing of the rain shade are shown in figures 1 and 2 respectively.

Performance Evaluation: Cobs of maize were spread directly under the device to serve as one of the agricultural produce that is being dried and protected. The sensor's open circuit was sprinkled with water which served as the rain water and the rain shade automatically opened and covered the cobs of maize. It retracted when the water dried up.

\section{RESULTS AND DISCUSSIONS}

The final torque transmitted by the geared D.C motor was evaluated to be $2290 \mathrm{Nmm}$. The gear parameters such as the number of teeth, pitch circle diameter, outside diameter, axial pitch, throat diameter and face width were determined to be $40,16 \mathrm{~mm}, 27.19 \mathrm{~mm}$, $12.57 \mathrm{~mm}, 23.19 \mathrm{~mm}$ and $32.03 \mathrm{~mm}$ respectively. The weight acting on each extension arm was found to be $12.5 \mathrm{~N}$. The roller tube inner and outer diameter were determined to be $45 \mathrm{~mm}$ and $50 \mathrm{~mm}$ respectively. The load acting on the stand was found to be $106.3 \mathrm{~N}$. Since it is less than the determined buckling load of $1195.5 \mathrm{~N}$, the stand is safe.

The results of the performance evaluation of the rain shade are depicted in Table1

.Table 1 Sprinkle, Response and Return time of the device with ambient temperature

\begin{tabular}{lllll}
\hline $\mathbf{S} / \mathbf{N}$ & $\begin{array}{l}\text { Ambient } \\
\text { Temperature }\left({ }^{\circ} \mathrm{C}\right)\end{array}$ & $\begin{array}{l}\text { Sprinkle } \\
\text { time(s) }\end{array}$ & $\begin{array}{l}\text { Response } \\
\text { time(s) }\end{array}$ & $\begin{array}{l}\text { Return } \\
\text { time }(\mathrm{s})\end{array}$ \\
\hline $\mathbf{1}$ & 28 & 1 & 0.5 & 1.50 \\
$\mathbf{2}$ & 30 & 5 & 1 & 41.1 \\
$\mathbf{3}$ & 30 & 10 & 1 & 470 \\
$\mathbf{4}$ & 30 & 20 & 1 & 480 \\
\hline
\end{tabular}

From the first reading of the response time in Table 1 , it was observed that the device responded to the water sprinkled and opened in $0.5 \mathrm{~s}$. This is due to the fact that enough water was made to touch the sensor 
and bridge the gaps of the circuit. But for other readings, as the sprinkle time increased, the response time was almost constant or within 1 second and the return time increased. However, the return time increased with varied ambient temperatures as these are evident in Table 1.
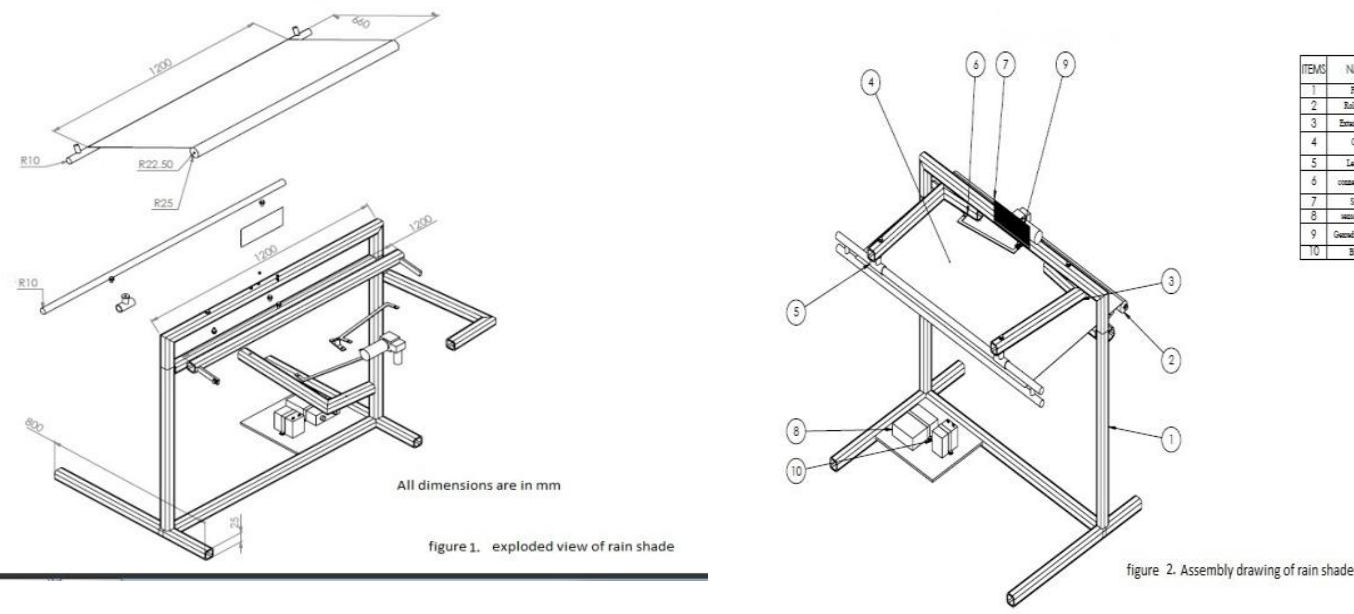

Conclusion: This investigation has shown that the rain shade constructed in this work is economically viable and can be used anywhere because of its compatibility, it requires little investment and is environmentally friendly. It can be used mostly in rural areas of some developing countries like Nigeria where the electricity supply is not reliable. It can be adapted for shading other drying materials from rain.

\section{REFERENCES}

Adebayo, A B (2014) Design and Fabrication of an Automatic Rain Shade. B.Eng Thesis submitted to the Department of Mechanical Engineering, Federal University of Technology Minna (Unpublished)

Alamu, O J, Nwaokocha, C N, Adunola, O (2014). Design and Construction of a Domestic Passive Solar Food Dryer . Avialable at http://ijs.academicdirect.org. Retrieved on $24^{\text {th }}$ November, 2014

Jayas, D S, Singh C B(2014). Drying of Agricultural products. Encylopedia of Agrophysics. :231-232

Khurmi, R S, Gupta, J K (2005). A Textbook of Machine Design, fourteenth Edition. Eurasia Publishing house(PVT) . LTD. Ram Nagar,New Delhi 2014.
Bhandari, V B (2014). Machine Design Data book, McGraw Hill Education(India) PVT LTD.

Hall, A S, Holowenko, A R, Laughlin, H G (2004). Shawn's Outline Series of Theory and Problems Of Machine Design. Tata McGrawHill Publishing Company Limited. New Delhi India.

Saeed, I E, Sopia, K , ZainolAbidin, Z (2008). Thin layer drying Drying of Roselle. Mathematical Modeling and Drying Experiments. Agricultural Engineering International: the CIGR Ejournal. Manuscript FP 08. 015 Vol. X

Sahari ,Y, Driscoll, R H(2013). Thin Layer Drying of Agricultural Products: A review. Third Malaysian Postgraduate Conference, 4-5 July, 2013 Sydney, New South Wales, Australlia. :821

Shear Stress of Some Materials. Available at http://www.woodsolutions.com. Retrieved on $20^{\text {th }}$ of September 